\title{
OS KAYAPÓ E O AMBIENTALISMO:LUTAS PELA TERRA EM SÃO FÉLIX DO XINGU-PA (1970-2000)
}

JOSÉ ROBERTO PORTO DE ANDRADE JÚNIOR ${ }^{1}$

UNIFAL, BRASIL

https://orcid.org/0000-0002-1862-2540

\begin{abstract}
RESUMO: $O$ objetivo desse artigo é analisar a relação entre o povo ameríndio Kayapó e o ambientalismo no processo histórico de disputas pela regularização territorial das áreas situadas em São Félix do Xingu-PA entre as décadas de 1970 e 2000. O referencial teórico adotado é a sociologia acontecimental, do campo da sociologia histórica. A principal técnica de pesquisa utilizada é a análise de documentos. O artigo defende que: a) antes da década de 1980, a retórica de proteção da natureza não ocupava lugar central nas disputas pelos territórios ameríndios, embora os Kayapó já tivessem consciência do caráter degradante da ocupação brasileira; b) no fim da década de 1980, houve a aproximação direta entre os Kayapó e grupos ambientalistas; c) a partir de então, a retórica "ambientalista" passou a ser central na justificação das demandas territoriais ameríndias, a despeito das contradições e disputas internas entre subgrupos do povo Kayapó; d) na década de 2000, os Kayapó mantinham práticas agrícolas tradicionais caracterizadas pelo caráter ambientalmente positivo e as combinavam com práticas e discursos produzidos no contexto da recente aproximação com o "ambientalismo".
\end{abstract}

PALAVRAS-CHAVE: Kayapó, ambientalismo, São Félix do Xingu-PA, lutas pela terra.

ABSTRACT: The aim of this article is to analyze the relationship between the Kayapo Amerindian people and environmentalism in the historical process of disputes over the territorial regularization of areas located in São Félix do Xingu-PA, between the 1970s and 2000s. The theoretical framework adopted is the eventful sociology, from the field of historical sociology. The main research technique used is document analysis. The article argues that: a) before the 1980 s, nature protection rhetoric did not occupy a central place in land disputes, although the Kayapo were already aware of the degrading nature of Brazilian occupation; $b$ ) in the endo f the 1980 s, there was a direct approximation between the Kayapó and environmental groups; c) from then on, the "environmentalist" rhetoric became central in the justification of Amerindian territorial demands, despite the contradictions and internal disputes between subgroups of the Kayapó people; d) in the 2000s, the Kayapó maintained traditional agricultural practices characterized by their environmentally positive character and combined them with practices and discourses produced in the context of the recent approximation to "environmentalism".

KEYWORDS: Kayapo, environmentalism, São Félix do Xingu-PA, fights for land.

\footnotetext{
${ }^{1}$ Doutor em Sociologia pela Universidade de São Paulo (USP). Professor da Universidade Federal de Alfenas-MG (Unifal-MG), campus de Varginha-MG. E-mail: jose.junior@unifal-mg.edu.br
} 


\section{Introdução}

No segundo semestre de 2020, a possibilidade de Raoni Metuktire,

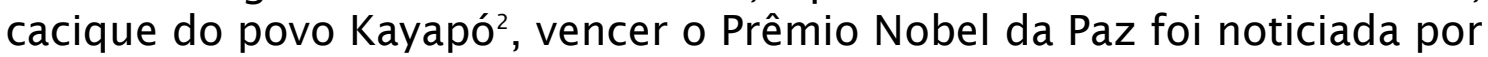
jornais brasileiros e estrangeiros. ${ }^{3} \mathrm{Um}$ ano após mais uma crise política gerada pela divulgação do aumento do desmatamento na Amazônia brasileira (em agosto de 2019), a referência à Raoni pode ser interpretada como um novo ato de valorização simbólica da atuação dos povos tradicionais na proteção do meio ambiente, ainda que o Nobel não tenha sido entregue ao ameríndio brasileiro.

A percepção de que os povos tradicionais contribuem com a proteção da natureza integra atualmente uma espécie de "senso comum" sobre os povos ameríndios e possui poucas vozes de contestação. Entretanto, a vinculação entre povos indígenas e proteção ambiental nem sempre foi hegemônica no imaginário social e na realidade política brasileira, sendo produto de uma construção histórica que demanda uma discussão científica mais aprofundada.

A relação entre povos ameríndios e proteção ambiental foi recentemente discutida no Dossiê "Antropologia das Áreas Protegidas e da Sustentabilidade", do Anuário Antropológico (Barreto Filho et al., 2020). Na literatura nacional, também existem interessantes estudos de caso sobre o tema (p. ex.: Pimenta, 2004), tal como ocorre na literatura estrangeira (Nadasdy, 2005). Entretanto, uma análise historicamente mais detalhada sobre o processo de vinculação entre a temática ameríndia e a temática ambientalista no Brasil ainda está por ser elaborada.

É sintomático desse distanciamento que trabalhos recentes sobre a história do movimento indígena no Brasil entre as décadas de 1970 e 2000 (p. ex.: Bicalho, 2010) não façam menção à incorporação da retórica ambientalista nas reivindicações territoriais ameríndias, tampouco discutam a articulação entre movimento indígena e ambientalista.

Nesse contexto, esse artigo busca contribuir com o debate sobre a relação entre os povos ameríndios e o ambientalismo por meio da análise dos processos históricos de disputa pela regularização territorial das áreas do povo Kayapó situadas no município de São Félix do Xingu-PA entre as décadas de 1970 e 1990. Nessas disputas, a associação entre a demanda territorial do povo Kayapó e a retórica da proteção à natureza,

\footnotetext{
${ }^{2}$ Os Kayapó são um povo ameríndio falante de uma língua pertencente à família linguística Jê, do tronco Macro-Jê. Eles denominam-se Mebêngôkre. Explica-se usualmente a etimologia da denominação "Kayapó" a partir dos estudos realizados por Terence Turner (Vidal, 1977, p. 14), para quem a palavra deriva-se de "k'aya" (macaco) e "po" (parecido, semelhante). Segundo Verswijver e Gordon, a origem mais provável da denominação seria a realização, pelos Mebêngôkre, de um "ritual ao longo do qual, durante muitas semanas, os homens kayapó, paramentados com máscaras de macacos, executam danças curtas" (Verswijver e Gordon, 2002). Mebêngôkre, por sua vez, deriva-se da composição entre o prefixo "Me", que designa uma coletividade de pessoas, o verbo "be", do tipo ser/estar, e os substantivos "ngô" (água) e "kre" (buraco), significando algo como "povo do buraco d'água" (Lea, 2012, p. 60). Atualmente, os Mebêngôkre aceitam amplamente a designação de Kayapó, que preferi adotar em razão de sua maior disseminação no Brasil e no mundo.

${ }^{3}$ Entre os veículos de comunicação brasileiros que noticiaram o fato, esteve a "Isto é". Disponível em: $<$ https://istoe.com.br/foi-por-pouco/>. Acesso em 13 jan 2021. Entre os veículos estrangeiros, a Reuters: $<$ https://www.reuters.com/article/us-brazil-environment-raoni-idUSKBN1VZ0FH>. Acesso em 13 jan 2021.
} 
tal como a articulação direta entre os ameríndios e grupos ambientalistas, tiveram grande importância para a conquista político-jurídica do território, conforme evidenciarei.

Ambientalismo é um termo utilizado na literatura acadêmica com variadas conceituações (cf. Almeida, 2004; Alonso, Costa e Maciel, 2007; Drummond, 1997; Viola, 1986). Para os fins deste trabalho, quatro "dimensões" do "ambientalismo" serão discutidas: a) dimensão cultural, correspondente aos valores, ideologias e ideias de proteção à natureza; b) dimensão material, correspondente às práticas produtivas de proteção à natureza; c) dimensão política, correspondente aos movimentos e grupos que atuam na proteção à natureza; d) dimensão discursiva, correspondente à utilização da retórica de proteção à natureza.

O referencial teórico adotado nesse trabalho é a "sociologia acontecimental", do campo da sociologia histórica. Caracterizado metodologicamente por William Sewell Jr., esse referencial situa-se na interface entre a Sociologia e a História, conjugando elementos dessas duas áreas científicas. Sewell Jr. explica que "descrições acontecenciais adequadas dos processos sociais se parecerão mais com histórias ou narrativas bem-feitas do que com leis da física", de modo que um dos propósitos principais do cientista social que trabalha com esse referencial teórico é "elaborar uma narrativa convincente sobre por que as coisas aconteceram do modo como aconteceram". Entre as categorias que orientam esse tipo de análise é possível destacar "tendências", "rotinas" e "acontecimentos". (Sewell Jr, 2017, p. 119-120)

Entre as principais técnicas de pesquisa utilizadas no desenvolvimento desse trabalho estão a elaboração de cronologia dos principais eventos do processo histórico de disputas pela demarcação das terras indígenas do povo Kayapó situadas em São Félix do Xingu-PA e a análise de documentos. Dentre os documentos analisados, destacam-se aqueles presentes nos processos administrativos de demarcação das terras indígenas (TI) situadas no município ${ }^{5}$, desarquivados junto à

\footnotetext{
${ }^{4}$ Tendências são definidas por Sewell Jr. como "mudanças direcionais nas relações sociais". Para ele, é possível observar em qualquer situação a existência de "várias tendências diferentes, com diferentes ritmos", que "podem estar causalmente relacionadas" ou "ser muito independentes uma da outra". Rotinas, por sua vez, são "atividades mais ou menos garantidas que tendem, em igualdade de condições, a ser repetidas indefinidamente dos mesmos modos". Segundo ele, "instituições em geral podem ser definidas como máquinas para a produção e manutenção de rotinas". Acontecimentos, por fim, são "sequências breves e intensas de interação social que têm efeitos de longa duração na história subsequente das relações sociais". Dito de outro modo, ainda segundo Sewell Jr., acontecimentos são "sequências temporalmente concentradas de ações que transformam estruturas", de modo a estabelecer novas rotinas e mudar as rotinas antigas, acelerar, reverter ou reorientar tendências (Sewell Jr, 2017, p. 270-272). Segundo Sewell Jr., "qualquer sequência histórica determinada tende a combinar uma pletora de tendências, rotinas e acontecimentos" e o trabalho do cientista social historicamente orientado é "determinar como esses vários processos temporais estão relacionados um com o outro dentro de uma sequência histórica real" (Sewell Jr, 2017, p. 272).

${ }^{5}$ Os seguintes processos administrativos de demarcação das terras indígenas situadas em São Félix do Xingu-PA foram desarquivados a meu pedido pela Fundação Nacional do Índio (FUNAI): processo $\mathrm{n}$. 1458/82, relativo à TI Menkragnoti; processo n. 3811/88, relativo à TI Trincheira/Bacajá; processo n. 1140/89, relativo à TI Kayapó; e processo n. 2412/97, relativo à TI Badjonkôre. Informações extraídas diretamente desses processos administrativos estão referenciadas, nesse trabalho, pela colocação do número do processo e da página onde se localiza a informação entre parênteses, como no exemplo a seguir: (proc. 2412/97, p. 151).
} 
Fundação Nacional do Índio (FUNAI), e os materiais jornalísticos contidos nos bancos de dados do Instituto Socioambiental (ISA) sobre as TI situadas em São Félix do Xingu-PA ${ }^{6}$. Realizei, além disso, pesquisa de campo no município de São Félix do Xingu-PA durante o ano de 2018, o que incluiu uma breve estada na TI Kayapó.

O artigo está estruturado em quatro tópicos, além da "Introdução" e da "Conclusão". No primeiro deles, intitulado "Os Kayapó e o 'ambientalismo' antes da década de 1980", discuto a autoconsciência dos Kayapó sobre suas próprias práticas produtivas e a frágil incorporação da retórica da proteção à natureza nas reivindicações territoriais anteriores à década de 1980. No segundo tópico, nomeado "Início das articulações diretas com ambientalistas", analiso os acontecimentos que marcaram o início da rotinização das articulações diretas entre lideranças dos Kayapó e grupos ambientalistas, no final da década de 1980. O terceiro tópico "Centralidade e contradições na 'ambientalização' Kayapó" - analisa tendências relevantes para uma compreensão realista da pluralidade da aproximação entre os Kayapó e o ambientalismo após o engajamento de interações constantes com grupos ambientalistas. Por fim, o último tópico do trabalho intitula-se "Tradição e modernidade no 'socioambientalismo' Kayapó" e analisa tendências materializadas durante a década de 2000.

\section{Os Kayapó e o "ambientalismo" antes da década de 1980}

São duas as tendências principais que caracterizam a relação entre os Kayapó e o "ambientalismo" antes da década de $1980 .{ }^{7}$ A primeira tendência diz respeito ao modo de organização societária e à cosmologia desse povo ameríndio: a partir do engajamento de interações constantes entre os Kayapó e a sociedade brasileira, os ameríndios desenvolveram uma percepção negativa sobre as dinâmicas de interação social com a natureza típicas da sociedade brasileira, tidas por eles como degradantes e prejudiciais à vida.

Em seu entrelaçamento com os ecossistemas regionais dos entornos do rio Xingu, os Kayapó construíram uma dinâmica de relação social com a natureza caracterizada pelo intenso conhecimento da realidade ecológica local, pelo baixo impacto negativo das intervenções antrópicas realizadas e pela promoção de heterogeneidade biológica por meio do manejo humano. O seminomadismo ("trekking") típico dos

\footnotetext{
${ }^{6}$ Utilizei os bancos de notícias jornalísticas do Instituto Socioambiental (ISA) referentes às seguintes terras indígenas situadas em São Félix do Xingu-PA: TI Kayapó (https://terrasindigenas.org.br/es/noticias/3731) e TI Menkragnoti (https://terrasindigenas.org.br/en/noticias/3952), com acesso entre agosto e dezembro de 2019. Informações extraídas dessas notícias jornalísticas estão referenciadas mediante a colocação entre parênteses do nome do jornal, da data da publicação e de uma referência ao ISA enquanto entidade organizadora do banco de dados, como no exemplo: (Folha de S. Paulo, 22/1/1990, ISA).

${ }^{7}$ Um detalhamento mais abrangente da história dos Kayapó foi feito por Vanessa Lea no livro "Riquezas intangíveis de pessoas partíveis: os Mebêngokre (Kayapó) do Brasil Central)" (Lea, 2012). Outro estudo importante que aborda a história dos Kayapó é o de Lux Vidal, "Morte e vida de uma sociedade indígena brasileira" (Vidal, 1977). Há, também, o artigo de Verswijver e Gordon, intitulado "Mebêngôkre (Kayapó)”, disponível no sítio eletrônico do Instituto Socioambiental (Verswijver e Gordon, 2002).
} 
Kayapó cumpriu papel importante para o baixo impacto de sua ocupação territorial, uma vez que grandes áreas de vegetação nativa próximas às suas moradas eram apenas ocasionalmente visitadas, no contexto das expedições periódicas. Além disso, inúmeras formas tradicionais de interação social com o ambiente materializavam as características ambientalmente benéficas do modo típico de relação social dos Kayapó com a natureza, associadas à promoção de heterogeneidade biológica: as roças policulturais baseadas na dinâmica natural de sucessão ecológica, as áreas de agricultura nômade, as ilhas de vegetação lenhosa no cerrado, entre outras (Posey, 1984, 1985, 1992, 1994).

Tais práticas materiais de interação com os ecossistemas estão associadas nos Kayapó a práticas simbólicas e ritualísticas que reforçam o direcionamento ambientalmente positivo da ação coletiva desse povo. Nesse sentido, segundo Posey, "os Kayapó preservam parte de sua bagagem de conhecimentos ecológicos por meio de mitos e rituais", uma vez que "alguns desses mitos tratam da relação entre homens, plantas e animais, e esses conhecimentos se manifestam também em cerimoniais, com seus símbolos, danças e canções". ${ }^{8}$ É possível observar nos mitos a interação permanente entre humanos e elementos bióticos e abióticos do ecossistema, relativamente indiferenciados e mutuamente implicados.

Entre os mitos exemplificativos dessa codificação simbólica de orientações que hoje entendemos como sendo uso sustentável dos recursos naturais, Posey destaca dois: segundo um importante mito Kayapó, "Bepkôrôrôti", espírito de um antigo xamã, ficaria irado quando os ameríndios não repartem seus alimentos, levando os Kayapó a abandonarem nas colmeias porções de mel, em homenagem ao xamã, o que facilitaria o reestabelecimento das colônias de abelhas; segundo outro mito, uma entidade mística chamada "Mry-kàák", a mais temida das criaturas sobrenaturais para os Kayapó, criaria "piabinhas" e bandos de peixe em desova, o que incentivaria os Kayapó a afastarem-se desses animais, facilitando a reprodução dos peixes, alimentos fundamentais na dieta desse povo ameríndio (Posey, 1992, p. 25-26).

Posey destaca que os Kayapó "acreditam que existe um equilíbrio entre os espíritos dos animais, dos homens e das plantas" e que se "os homens abusarem dos recursos da floresta, a harmonia será destruída e chegarão doenças para toda a tribo" (Posey, 1984, p. 37).

Partindo dessa realidade material e simbólica de entrelaçamento com os ecossistemas regionais, os Kayapó passaram a ser confrontados com a devastação florestal para instalação de monocultivos na década de 1970, quando a expansão da fronteira agropecuária na Amazônia intensificou-se e atingiu as adjacências de São Félix do Xingu-PA. Em resposta a essa situação, os Kayapó desenvolveram uma percepção cultural marcada pela diferenciação entre seu modo típico de vida e o modo típico de vida da sociedade brasileira do entorno de suas áreas de vivência, consolidando uma nova visão social de mundo caracterizada por essa oposição.

\footnotetext{
${ }^{8}$ Uma abrangente catalogação dos mitos do povo Kayapó foi realizada na década de 1930 por Horace Banner, missionário que trabalhou com a evangelização de grupos de Kayapó (Banner, 1957).
} 
Segundo o antropólogo Terence Turner, após o estabelecimento de relações permanentes com a sociedade brasileira, a visão de mundo Kayapó passou a ser trabalhada a partir de "uma nova totalidade 'social' dramaticamente dividida entre 'índios' (os próprios Kayapó e outros povos indígenas) de um lado e a sociedade brasileira de outro" (Turner, 1991 , p. 80). Ainda segundo ele, essa nova visão de mundo expressava a compreensão de que a relação ameríndia é "construtiva, consistindo em processos de transformação tradicional de matérias e energias naturais em poderes e formas sociais, de modo que permitam a contínua renovação da natureza e de suas forças", enquanto "a dos brasileiros, por outro lado, é destrutiva: a derrubada de florestas e sua conversão em pastagens, a poluição dos rios, a mineração da terra, ou o represamento dos rios e a inundação das terras vizinhas à sua volta, tudo o que destrói a natureza e a torna imprópria para habitação, agricultura, caça ou pesca" (Turner, 1991, p. 80).

Relatórios antropológicos do final da década de 1970, relativos a demandas de regularização territorial de áreas situadas no município de São Félix do Xingu-PA, evidenciam essa percepção negativa dos ameríndios Kayapó. Um desses relatórios, subscrito pelo antropólogo Gustaaf Verswijver em 1977, afirma que os Kayapó não queriam morar perto de fazendeiros, a quem eles se referiam como "pessoas que comem o mato" e como "aqueles que acabam com os nossos animais" (proc. $1458 / 82$, p. 174).

A segunda tendência principal que caracteriza a relação entre os Kayapó e o "ambientalismo" antes da década de 1980 diz respeito à utilização episódica e periférica da retórica da proteção à natureza como justificativa para as demandas de regularização territorial dos Kayapó. Não havia centralidade na associação entre a demanda por regularização territorial e a retórica "ambientalista" nos discursos reivindicatórios desse período.

Antes da década de 1950, não houve no Brasil nenhum episódio relevante de associação entre demandas territoriais de povos ameríndios e a retórica da proteção à natureza (ANDRADE JÚNIOR, 2020). Um acontecimento da primeira metade do século $X X$ que exemplifica essa tendência de desvinculação entre as temáticas foi a posição pública tomada em 1907 por Hermann von Ihering, então diretor do Museu Paulista e um dos cientistas naturais mais influentes do período, defendendo e justificando o extermínio dos ameríndios que se recusassem a submeter-se ao avanço da sociedade brasileira. Para lhering, os indígenas não poderiam dar qualquer contribuição à civilização, sendo, ao contrário, "um empecilho para a colonização das regiões do sertão que habitam", de modo a não haver "outro meio, de que se possa lançar mão, senão o seu extermínio" (Ribeiro, 1985, p. 119).

O evento que inaugurou a tendência de associação entre demandas territoriais de povos ameríndios e a retórica da proteção à natureza foi o processo político que resultou na criação do Parque Nacional do Xingu, formalmente constituído pelo Decreto n. 50.455/1961 e situado no norte do estado de Mato Grosso, ao sul de São Félix do Xingu-PA. 
Nesse processo político, a referência à retórica da proteção da natureza e a utilização da justificativa de preservação de exemplares da flora e da fauna típicos da região Central do Brasil foram decisivas, como evidenciam os principais documentos relativos à tramitação da proposta (Garfield, 2005; Menezes, 2000). ${ }^{9}$ A própria nomenclatura atribuída à área protegida ameríndia ("Parque Nacional") foi extraída da legislação florestal então vigente (Código Florestal de 1934) e, segundo Menezes, a proposta inspirava-se na "experiência norte-americana de criação de 'reservas florestais indígenas', onde a ideia da preservação do habitat indígena acopla-se à de proteção ambiental" (Menezes, 2000, p. 108).

No mesmo ano em que foi formalizado o Parque Nacional do Xingu, a criação de seis "reservas florestais" pelo então presidente Jânio Quadros deu continuidade à tendência estatal de associação entre propostas de regularização territorial de áreas ameríndias e o tema da proteção à natureza. As "reservas florestais" foram um novo tipo de área protegida, não previstas no Código Florestal de 1934, e os seus decretos de criação afirmavam que "as terras, a flora, a fauna e as belezas naturais na área a ser demarcada ficam, desde logo, sujeitas ao regime especial estabelecido pelo Código Florestal".

Uma das "reservas florestais" criadas juridicamente em 1961 foi "Gorotire" (Decreto n. 51.029/1961), nome de um dos principais subgrupos do povo Kayapó, com morada em São Félix do Xingu-PA. Os Kayapó não participaram diretamente da formulação da proposta da "reserva florestal" e, apesar de sua criação formal, não houve consequências práticas de sua decretação, no que tange à regularização territorial desse povo.

No final da década de 1970, a presença de referências à retórica da proteção à natureza tornou-se mais intensa nos processos administrativos que tramitavam objetivando a regularização territorial das áreas Kayapó situadas em São Félix do Xingu-PA. Em laudo antropológico de 1977, subscrito por Gustaaf Verswijver, consta a afirmação de que a área demarcada seria "também uma reserva natural, uma área de preservação da riqueza natural nessa parte do Brasil" (proc. 1458/82, p. 179). Em laudo antropológico subscrito por Saul Carvalho Lopes, de 1978, consta a afirmação de que "a área delimitada e eleita como Reserva Indígena Kayapó, além de proporcionar adequada

\footnotetext{
${ }^{9}$ No início da década de 1950, o então vice-presidente de Getúlio Vargas, Café Filho, solicitou a elaboração de um anteprojeto de lei sobre a proteção dessa região do alto Xingu a um grupo presidido pelo Brigadeiro Raimundo Vasconcelos Aboim, e composto por Heloísa Alberto Torres (antropóloga e então diretora do Museu Nacional), Orlando Villas Boas e Darcy Ribeiro. O anteprojeto foi entregue em abril de 1952. Segundo seus autores, o Parque Nacional do Xingu, idealizado para a área, seria "um tipo singular de Parque que difere tanto dos chamados 'Parques Nacionais' quanto das Reservas Indígenas, do Brasil e do estrangeiro", sendo "caracterizado pela proteção ao elemento indígena, como se apresenta em sua feição humana, em sua feição faunística e em sua feição florística” (Menezes, 2000, p. 344). Um relatório posterior, de 1961, sobre a proposta de criação dessa área protegida no Xingu consignou, no mesmo sentido, que "encontram-se na região todos os representantes topográficos e vegetais do Brasil Central", que "a fauna brasileira, que apresenta sinais de extermínio em grandes áreas do País, terá no Parque Indígena do Xingu a garantia de sua sobrevivência", e que na área "encontram-se representantes dos quatro grupos linguísticos sul americanos: Tupí, Caribe, Gê e Aruac", destacando a convergência entre a proteção da flora, da fauna e dos povos indígenas que o Parque traria (Menezes, 2000, p. 384).
} 
subsistência aos indígenas constitui-se em uma Reserva Biológica de grande importância para o Brasil" (proc. 2412/97, p. 119).

$\mathrm{O}$ aumento da presença de referências diretas à proteção da natureza como justificativa para a demarcação dos territórios ameríndios do povo Kayapó situados em São Félix do Xingu-PA no final da década de 1970 vincula-se à ampliação da importância da temática ambientalista a nível nacional e internacional nesse período, posteriormente à ocorrência da Conferência das Nações Unidas sobre o Meio Ambiente Humano (chamada popularmente de "Conferência de Estocolmo"), em 1972. A Conferência foi um marco para o movimento ambientalista global e, a partir de então, essa temática disseminou-se por todo o mundo.

Entretanto, essas referências mantiveram-se periféricas nas formulações discursivas de justificação das demandas territoriais nesse período e eram protagonizadas por agentes diversos dos próprios ameríndios: antropólogos, cientistas e outros agentes estatais.

\section{Início das articulações diretas com ambientalistas}

Um conjunto de eventos ocorridos na segunda metade da década de 1980 marcou o início da rotinização das interações diretas entre os Kayapó e grupos ambientalistas, caracterizando a formação de uma tendência de articulação política perene entre esses agentes que trouxe mudanças significativas para os Kayapó situados em São Félix do XinguPA.

Foram três os acontecimentos principais a demarcar o início dessa tendência: a exposição "A ciência Mebêngôkre: alternativas contra a destruição", ocorrida em 1987, e as articulações internacionais realizadas após este evento; o chamado "10 Encontro das Nações Indígenas do Xingu", ocorrido em 1989 no município de Altamira-PA; e a turnê internacional promovida pelo cantor britânico Sting e a liderança Kayapó Raoni Metuktire, também em 1989.

A exposição "A ciência Mebêngôkre: alternativas contra a destruição" foi realizada no Museu Emílio Goeldi para apresentação dos resultados de estudos multidisciplinares chamados de "Projeto Kayapó", iniciados em 1982 sob coordenação do norte-americano Darrel Posey. Segundo Posey, esses estudos visaram "documentar o conhecimento Kayapó acerca de plantas medicinais, agricultura, classificação e uso do solo, sistemas de reciclagem de nutrientes, formação de solos enriquecidos para a agricultura, métodos de reflorestamento, pesticidas e fertilizantes naturais, comportamento animal, melhoramento genético de plantas cultivadas e semidomesticadas, manejo de pesca e da vida selvagem e astronomia", com envolvimento de "cerca de 20 cientistas e técnicos de pesquisa" (Posey, 1992, p. 19).

A divulgação dos resultados do "Projeto Kayapó" impulsionou a associação nacional e internacional entre as formas típicas de manejo promovidas por esses ameríndios e o tema da proteção à natureza, fortalecendo o entendimento de que o modo tradicional de relação social desse povo com os ecossistemas nativos era ecologicamente positivo. 
Em 1988, em virtude da grande repercussão da exposição, lideranças dos Kayapó foram convidados a participar de um simpósio internacional sobre manejo de florestas tropicais, promovido pela Universidade da Flórida, nos Estados Unidos. Após o simpósio, grupos ambientalistas norte-americanos convidaram lideranças Kayapó para visitarem Washington e para participarem de reuniões com representantes do Banco Mundial, do Departamento do Tesouro dos Estados Unidos e com membros do Congresso Nacional norte-americano. Esse conjunto de encontros sobre temas ambientais marcou, segundo Schmink e Wood, a introdução dos Kayapó na seara das relações públicas internacionais (Schmink e Wood, 1992, p. 271).

Em 1989, os Kayapó - sob a liderança do cacique Paulinho Payakan - sediaram o "10 Encontro das Nações Indígenas do Xingu", um evento de protesto contra um projeto de construção de uma barragem no sul do Pará, que contou com a participação de representantes de "24 povos indígenas, além de grupos ambientalistas de vários países" (Verswijver e Gordon, 2002). O evento evidenciou a habilidade política dos Kayapó em sintetizar o tradicional e o contemporâneo, o local e o global, ao conjugar uma série de demonstrações ritualísticas do povo Kayapó com ampla cobertura jornalística internacional. Por meio desse evento, a posição dos Kayapó de oposição à instalação da barragem em virtude das consequências ambientalmente degradantes da obra foi globalmente divulgada.

Ainda em 1989, após o encontro de Altamira-PA, Raoni Metuktire engajou-se com o cantor britânico Sting numa turnê internacional por 17 países (dentre os quais França, Suíça, Itália, Inglaterra, Estados Unidos, Canadá, Austrália e Japão). Durante a turnê, eles reuniram-se com importantes lideranças mundiais, como François Mitterrand (presidente da França), príncipe Charles (da Inglaterra), rei Juan Carlos (Espanha) e o papa João Paulo II. A motivação da turnê foi a alegação do então presidente Sarney, em 1988, de que não havia recursos para realização dos atos técnicos necessários para demarcação dos territórios indígenas do povo Kayapó. A turnê deu grande visibilidade para a reivindicação dos Kayapó pela regularização dos seus territórios e, com ela, recursos financeiros foram obtidos (A Tarde, 9/5/1990, ISA).

Esses acontecimentos ocorreram no contexto das mudanças vivenciadas na década de 1980 no Brasil e no mundo. Entre essas mudanças, destaca-se a redemocratização brasileira, com ampliação das possibilidades de protesto e de ação política no país, tornando possível que as ações das lideranças ameríndias e dos grupos ambientalistas ocorressem sem censuras diretas ou impedimentos típicos do período ditatorial. No mesmo período, modificou-se também a dinâmica de interação entre o Brasil e a ordem internacional, com ampliação da abertura nacional à entrada de capitais estrangeiros, o que tornou as decisões brasileiras mais suscetíveis de influência internacional, num contexto em que a problemática ambiental ganhava cada vez mais importância e em que a Amazônia foi alçada ao centro das discussões globais em virtude da divulgação de dados do desmatamento (ANDRADE JÚNIOR, 2020). 
Importante frisar, também, que a articulação dos Kayapó com grupos ambientalistas não consistiu numa iniciativa isolada desse povo, mas na manifestação de uma tendência conjuntural de um período da história brasileira caracterizado pela intensificação da associação entre as demandas territoriais das populações tradicionais e a retórica da proteção à natureza. Outro exemplo de importante população tradicional que "ambientalizou" seus discursos de reivindicação territorial no mesmo período é o dos seringueiros (cf. Cunha e Almeida, 2001).

\section{Centralidade e contradições da "ambientalização" Kayapó}

Nos anos que se seguiram aos acontecimentos que marcaram o início da aproximação entre os ameríndios e grupos ambientalistas, foi perceptível a ocorrência de duas tendências entre os Kayapó de São Félix do Xingu-PA cuja caracterização contribui para uma adequada compreensão da "ambientalização" dos Kayapó.

Uma primeira tendência diz respeito à centralidade que a retórica de proteção à natureza passou a ter nos processos de disputa pela regularização dos territórios desse povo ameríndio. A partir da década de 1990, o discurso "ambientalista" passou a ocupar uma posição central nas reivindicações territoriais dos Kayapó, tendência continuada nas décadas seguintes.

Nos documentos juntados aos processos administrativos que visavam a regularização territorial das áreas situadas no município de São Félix do Xingu-PA, as propostas desse período passaram a conter - como regra - um ou mais itens de ponderação "ambientalista". Um relatório antropológico de 1998, subscrito por Eliane da Silva Souza, por exemplo, contemplou um item específico sobre "meio ambiente", no qual discutiu a "preservação ambiental" e a "visão ecológica dos Mebengokré". Segundo ela:

a proteção ambiental servirá, também, para conter o avanço das frentes de ocupação não indígena, em direção ao rio Xingu. Caso isto não ocorra, em poucos anos a ocupação por fazendas na faixa entre o rio Fresco e o rio Xingu acabará por gerar impactos significativos neste último em relação à qualidade e quantidade das águas como resultado de desmatamentos, não utilização de práticas de conservação do solo, assoreamento dos rios e igarapés e diminuição da biodiversidade local. [...] Pelo que foi exposto temos que a área em questão é de relevante importância ambiental para o ecossistema do rio Xingu. (proc. 2412/97, p. 366)

As referências dos próprios Kayapó ao caráter ambientalmente negativo do modo de vida dos brasileiros e ao caráter ambientalmente positivo dos ameríndios também passaram a estar presentes com mais destaque nos relatórios antropológicos dos anos 1990. 
Relatório antropológico de 1996 faz menção aos seguintes relatos de ameríndios Kayapó: "A água, o mato e os rios são nossos, os brancos vieram de longe, não entendem nada, invadem e estragam o mato e os rios que são nossos e que sempre cuidamos", de lobal, da aldeia Kapôt; "O branco tem fome de madeira e ouro. Eles querem nossa terra para ganhar dinheiro. Nós vivemos aqui e cuidamos da terra para nossos filhos e netos possam continuar vivendo aqui", de Jôdi, da aldeia Metyktire; "O branco queima o mato para plantar capim e criar gado. Quem paga nossa terra estragada? E a nossa água suja?", de Yaboti, da aldeia Metyktire; "O branco chegou e queimou o mato bom, queimou jabutis, queimou pacas, queimou filhotes de papagaio, está estragando tudo. O lugar do branco é na cidade. Quando a gente precisa ir à cidade, a gente não estraga cidade. Por que o branco pode vir estragar nosso mato? Ele não pode.", de Krumare (proc. 2412/97, p. 238-252).

Essa dupla aproximação que passou a caracterizar a vinculação entre os Kayapó e o "ambientalismo" - a articulação política direta com grupos ambientalistas e a atribuição de centralidade à retórica da proteção à natureza nas reivindicações territoriais pelos próprios ameríndios e por outros agentes - foi essencial para as conquistas obtidas a partir do início da década de 1990, dentre as quais se destacam as homologações presidenciais da demarcação de terras indígenas situadas em São Félix do Xingu-PA: TI Kayapó em 1991 (Decreto n. 316/1991); TI Menkragnoti em 1993 (Decreto - não numerado - de 9 de agosto de 1993) e TI Trincheira/Bacajá em 1996 (Decreto - não numerado - de 2 de outubro de 1996).

Os acontecimentos do final da década de 1980, anteriormente referidos, foram indispensáveis para essas conquistas, uma vez que a exposição "A ciência Mebêngôkre: alternativas contra a destruição" forneceu o fundamento científico que legitimou as articulações que se seguiram, embasando tecnicamente a associação entre a cultura Kayapó e a retórica da proteção da natureza, enquanto a turnê internacional entre Sting e Raoni possibilitou que a visibilidade midiática da demanda atingisse importantes audiências internacionais e que recursos materiais fossem arrecadados para a regularização territorial das terras indígenas.

Segundo noticiário da época, foram arrecadados na turnê "cerca de três milhões de dólares" e, com os recursos, foi constituída a Fundação Mata Virgem, que contribuiu materialmente com os processos de regularização das terras indígenas mediante a realização dos atos técnicos de medição e demarcação territorial (A Tarde, 9/5/1990, ISA). Ainda segundo notícia da época, "pela primeira vez no Brasil, a demarcação de uma reserva indígena não foi feita pela União e sim por uma organização não governamental (ONG)", a Fundação Mata Virgem, no caso da terra indígena Menkragnoti, com o custo de US\$ 650.000,00 para realização dos atos necessários à demarcação (O Globo, 26/12/1992, ISA).

A outra tendência que caracterizou a realidade dos Kayapó de São Félix do Xingu-PA nos anos que se seguiram ao início da aproximação desses ameríndios com grupos ambientalistas e que ajuda a compreender a materialidade dessa relação diz respeito à continuidade do engajamento 
de subgrupos de Kayapó em iniciativas de exploração extrativa de madeira e minério nos territórios sob domínio ameríndio.

Desde o início da década de 1980, alguns subgrupos e algumas lideranças do povo Kayapó notabilizaram-se pela associação com agentes econômicos interessados na exploração do território ameríndio. O mais famoso desses ameríndios foi Tutu Pombo, cacique notabilizado por permitir a entrada de madeireiras e mineradoras nos domínios submetidos ao controle de seu subgrupo, mediante o pagamento de compensação financeira. Em 1982, um acordo formal chegou a ser assinado entre Pombo e uma dessas empresas, prevendo o pagamento de $5 \%$ do valor da produção às comunidades ameríndias. Tal acordo é considerado o primeiro do tipo formulado em áreas ameríndias brasileiras (Schmink e Wood, 1992, p. 266).

Após a aproximação entre os Kayapó e grupos ambientalistas e após a atribuição de centralidade à retórica da proteção à natureza nos processos políticos de reivindicação pela regularização dos territórios ameríndios, essas associações entre subgrupos Kayapó e agentes interessados na exploração extrativista do território continuaram existindo, protagonizadas por Pombo e por outras lideranças. Tal situação deu origem a uma disjuntiva entre grupos Kayapó que tinham visões e interesses diversos sobre a utilização de seus territórios e que passaram a protagonizar conflitos e disputas entre si.

Um evento importante que caracteriza essa disjuntiva ocorreu em 1990, quando numa reunião realizada com dezenas de caciques Kayapó, Raoni Metuktire teria sido desautorizado a falar em nome dos Kayapó e Tutu Pombo teria sido indicado como o seu novo porta-voz, segundo noticiário da época (Estado de $S$. Paulo, 9/6/1990, ISA). Essa "reorganização política" dos Kayapó foi articulada por Pombo durante a viagem internacional de Raoni e Sting, momento em que Pombo fortaleceu sua ascendência sobre os ameríndios ao viajar pelas aldeias distribuindo "alimentos, remédios e promessas" e censurando a postura preservacionista de Raoni (Estado de S. Paulo, 6/1990, ISA). O estopim para a cisão teria sido uma mensagem de Raoni criticando os Kayapó envolvidos em negócios com madeireiras e garimpeiros (Jornal da Tarde, 2/6/1990, ISA). Alguns meses depois da cisão, houve a reconciliação entre Pombo e Raoni, mediada por Paulinho Payakan e por funcionários da FUNAI, reposicionando Raoni como principal porta-voz entre os ameríndios Kayapó (O Liberal, 21/10/1990).

A despeito dessa "conciliação", as diferenças de entendimento continuaram existindo e a associação entre grupos de Kayapó e madeireiras e garimpeiros foi midiaticamente explorada durante toda a década de 1990, visando o enfraquecimento das pretensões territoriais dos Kayapó, em benefício dos grupos interessados em ocupar o território desse povo. ${ }^{10}$

\footnotetext{
${ }^{10}$ Um exemplo é um artigo de opinião divulgado no famoso jornal "The Wall Street Journal”, no final de 1994, relatando a associação entre os Kayapó e madeireiros, com ampla repercussão na mídia brasileira. Sobre o assunto, entre outras notícias, há a publicação da revista Exame (Exame, 18/1/1995, ISA). Na mesma linha, há publicações da década de 2000, tais como a do jornal "O Estado de São Paulo" (OESP, 31/1/2002, ISA) e a do jornal “O Liberal”, do Pará (O Liberal, 8/5/2004, ISA).
} 


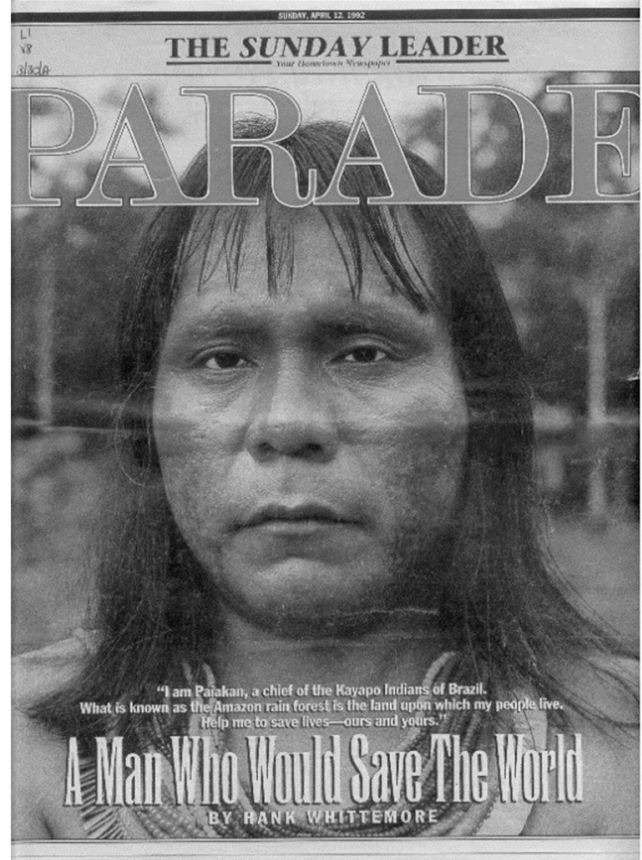

Figura 1. Capa da revista "Parade", $1980^{11}$

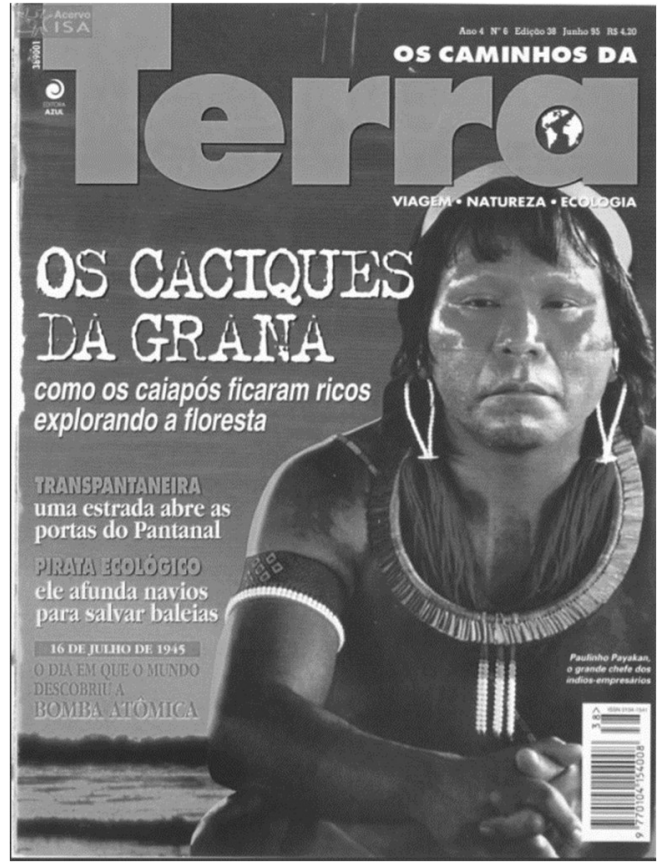

Figura 2. Capa da revista "Terra", $19944^{12}$

A simplificação da problemática da relação entre os Kayapó e a proteção do meio ambiente operada por essas divulgações distorcia a complexa realidade societária do povo Kayapó, tal como a simplificação operada por uma divulgação vulgar dos indígenas como "bons selvagens" ou "ecológicos por vocação" o fizera anteriormente.

As práticas culturais dos Kayapó não respondem à mesma racionalidade e nem se vinculam às mesmas premissas do pensamento "conservacionista". O "ambientalismo" dos Kayapó associa-se a seu modo típico de organização societária, indissociável dos ecossistemas nativos e incompatível com o desflorestamento que caracteriza a expansão da fronteira agropecuária. A adoção com centralidade da retórica da proteção à natureza pelos Kayapó e sua aproximação com grupos ambientalistas deu-se no contexto da identificação de afinidades eletivas entre esses distintos agrupamentos humanos e no aproveitamento das oportunidades políticas disponibilizadas pela conjuntura, sem que houvesse identificação completa de pautas e de premissas entre eles. $\mathrm{Na}$ síntese de Verswijver e Gordon sobre essa disjuntiva:

da perspectiva dos índios, alinhar-se com os ambientalistas e negociar com a economia local com a qual convivem de longa data faz igualmente parte de

\footnotetext{
11 Capa com foto do cacique Kayapó Paulinho Payakan. Disponível em: $<$ https://hankmemoir.wordpress.com/2010/01/21/fighting-for-the-rainforest-the-kayapo-tribe-and-a-manwho-would-save-the-world/>. Acesso em 13 jan 2021.

12 Capa com foto do cacique Kayapó Paulinho Payakan. Acesso em 13 jan 2021. Disponível em: $<$ https://documentacao.socioambiental.org/noticias/anexo_noticia/18237_20110112_161428.pdf>.
} 
suas estratégias de relacionamento com o mundo dos brancos, parte do seu modo de enfrentar as novas condições históricas que se lhes apresentam. $\mathrm{Na}$ ausência de uma política governamental para a questão indígena, os Kayapó trataram de obter por conta própria recursos (simbólicos, políticos e econômicos) fundamentais para sua reprodução social. Não apenas bens de consumo, serviços, atendimento médico, mas também possíveis parceiros e colaboradores. Daí a necessidade de chamar atenção internacional para o problema da demarcação de suas terras, para quem estava disposto a ouvir. Daí negociar parte dos recursos naturais de suas terras em troca de dinheiro. Além disso, as idealizações (positiva ou negativa) dos brancos não permitiam enxergar que essas estratégias nunca foram consensuais, provocando muitas vezes conflitos internos, e até cisões nas comunidades, entre os partidários de um ou outro tipo de atuação. Os Kayapó não são um bloco monolítico de pensamento e atitudes. É preciso entender suas ações e estratégias tanto no contexto de sua "política externa" (luta por autonomia e afirmação étnica), quanto no de sua "política interna", que envolve também disputas por prestígio entre lideranças intra e interaldeãs e grupos de idade. (Verswijver e Gordon, 2002)

\section{Tradição e modernidade no "socioambientalismo" Kayapó}

A partir da década de 2000, três tendências principais marcaram a associação entre o povo Kayapó e o "ambientalismo" nas disputas pela terra travadas em São Félix do Xingu-PA. A primeira delas diz respeito à diminuição do engajamento de ameríndios Kayapó em iniciativas de exploração extrativa de madeira e minério nos territórios sob domínio ameríndio.

Essas iniciativas continuaram existindo, trazendo problemas ambientais e sociais graves para as comunidades do entorno e gerando poucos benefícios econômicos como contrapartida. Segundo o Greenpeace, respaldado em publicações jornalísticas do período, as madeireiras que se associavam aos Kayapó praticavam, em regra, negociações econômicas bastante vantajosas a elas, pagando somente cerca de $\mathrm{R} \$ 80,00$ (US\$30,00) por árvore, cuja madeira cerrada valia mais de US\$3.300,00 no mercado internacional (Greenpeace, 2001, p. 4).

Um evento ocorrido em 2006 ilustra a continuidade dessa aproximação entre subgrupos Kayapó e exploradores extrativistas: a Polícia Federal suspendeu uma operação em curso em terras indígenas de São Félix do Xingu-PA em virtude da "disputa entre índios", uma vez que um grupo de ameríndios da aldeia Gorotire apoiava a permanência de garimpos na terra indígena, enquanto "os caciques das demais aldeias 
apoiam o trabalho dos órgãos federais e discordam da postura adotada pelos chefes de Gorotire" (Correio Braziliense, 11/8/2006, ISA).

Entretanto, as ocorrências desses eventos diminuíram bastante, ao mesmo tempo que foram ampliadas as iniciativas dos ameríndios Kayapó de combate às invasões não consentidas dos seus territórios por garimpeiros, madeireiras e unidades de produção agropecuária. Em diversas oportunidades, inclusive, os Kayapó fizeram uso da força física e da violência para intimidar e expulsar os invasores, conforme amplamente divulgado na mídia. ${ }^{13}$

Nesse contexto, houve diminuição da exploração madeireira e garimpeira nas TI do povo Kayapó situadas em São Félix do Xingu-PA (Schwartzman e Zimmerman, 2005, p. 167).

Outra tendência importante da década de 2000 , no que tange à aproximação entre o povo Kayapó e o "ambientalismo", diz respeito às inovações práticas e discursivas que surgiram no contexto da continuidade da atribuição de centralidade à retórica "ambientalista" nas demandas de regularização territorial dos povos ameríndios.

No início da década de 2000, os Kayapó receberam das instituições estatais treinamento e capacitação para participação em ações de fiscalização das terras indígenas (Funai, 29/8/2002, ISA), o que ampliou o engajamento desses grupos nas ações de defesa do território. Em 2008, ocorreu, pela primeira vez, a atuação de uma brigada indígena no combate às queimadas, a partir de capacitação promovida pelos Bombeiros. A iniciativa, liderada por Raoni, resultou, segundo noticiário da época, na redução de $80 \%$ das queimadas nas terras dos Kayapó, fomentando sua ampliação (Agência Brasil, 22/9/2008, ISA).

Iniciativas de exploração econômica sustentável dos ecossistemas de vegetação nativa situados nas terras dos ameríndios Kayapó também ocorreram com mais intensidade na década de 2000, com destaque para ações visando a exploração sustentável da madeira (Gazeta Mercantil, $5 / 11 / 1997$, ISA), o aproveitamento do potencial turístico das áreas (O Popular, 6/9/2002, ISA), o comércio de sementes de espécies nativas (Funai, 1/9/2003, ISA), a comercialização de óleos de castanha e copaíba, mel e pequi beneficiado (Funai, 3/8/2005, ISA). O Instituto Raoni, criado em 2001, passou a ser um importante polo de aglutinação e incentivo a essas iniciativas (Amazônia.org.br, 23/2/2006, ISA).

Raoni Metuktire prosseguiu sendo a principal liderança das reivindicações territoriais dos Kayapó e da justificação ambientalista de suas demandas, realizando viagens internacionais e nacionais para discussão do tema com diversas lideranças políticas. ${ }^{14}$

\footnotetext{
${ }^{13}$ São inúmeras as notícias jornalísticas nesse sentido. Em 2002, por exemplo, o jornal O Estado de São Paulo noticiou a iminência de um conflito entre os Kayapó e pescadores que teriam invadido o território dos ameríndios (OESP, 17/8/2002, ISA). Em 2004, a Funai noticiou um conflito com garimpeiros (Funai, 29/4/2004). Em 2005, a Folha de São Paulo noticiou disputas com fazendeiros (FSP, 10/12/2005, ISA), etc. ${ }^{14}$ Em 2000, por exemplo, Raoni foi recebido por Jacques Chirac, presidente da França, para discutir a colaboração desse país europeu com iniciativas de melhoria da vida do povo Kayapó (Veja, 17/5/2000, ISA). Em 2002, Raoni esteve novamente na França, recebido pelo Secretário de Relações Exteriores para pedir "apoio financeiro para defender sua reserva dos madeireiros e pescadores ilegais" (Jornal do Brasil, 26/11/2002, ISA).
} 
$\mathrm{E}$ as conquistas territoriais prosseguiram ocorrendo. $\mathrm{A} \mathrm{TI}$ Badjonkôre, de 2.220 km², situada em São Félix do Xingu-PA e Cumarú do Norte-PA, teve a homologação presidencial da demarcação formalizada por meio do Decreto de 23 de junho de 2003.

Uma última tendência relevante da década de 2000 diz respeito à manutenção entre os Kayapó de diversas de suas práticas agrícolas tradicionais, caracterizadas pela promoção de heterogeneidade biológica e pela replicação da lógica da sucessão da vegetação nativa na produção dos cultivos.

Segundo estudo publicado em 2012, os Kayapó da região do Xingu mantinham no século XXI cultivos com ampla biodiversidade em roças e em áreas de agricultura nômade, tal como ocorrido tradicionalmente entre os ameríndios desse povo (Robert, De et al., 2012).

Comparando os dados encontrados sobre diversidade de espécies nesse estudo, realizado na década de 2000, com os dados encontrados por estudos de etnobotânica dos séculos XIX e XX, os pesquisadores concluíram que "não estamos presenciando a erosão dessa agrodiversidade - e, portanto, dos conhecimentos associados - como supúnhamos no começo do estudo, mas, ao contrário, a ampliação da lista de nomes de plantas ou o crescimento das reservas locais de diversidade agrícola" (Robert, De et al., 2012, p. 362).

Portanto, uma interessante síntese entre tradição e modernidade passou a ser materializada na prática produtiva "ambientalista" do povo Kayapó situado em São Félix do Xingu-PA, combinando ações seculares de baixo impacto negativo e de promoção de biodiversidade biológica com as novas ações produzidas no contexto da aproximação com grupos ambientalistas e direcionadas ao combate das práticas extrativistas.

O êxito dessa combinação é evidenciado pelo baixo desmatamento presente nas $\mathrm{TI}$ relacionadas ao povo Kayapó nesse período. $\mathrm{Na} \mathrm{TI}$ Kayapó, o desmatamento acumulado até 2010 foi de 136,01 km², equivalentes a apenas $0,49 \%$ da área dessa TI. Na TI Menkragnoti, o desmatamento acumulado até 2010 foi de $34,04 \mathrm{~km}^{2}$, equivalentes a somente $0,08 \%$ da área total dessa TI. Na TI Trincheira/Bacajá, o desmatamento acumulado até 2010 foi de $150,27 \mathrm{~km}^{2}(0,88 \%$ da área da TI). Na TI Badjonkôre, o desmatamento após sua criação, em 2003, no período $2004-2010$, foi de $4,85 \mathrm{~km}^{2}$, equivalentes a somente $0,36 \% \mathrm{da} \mathrm{TI}$. $\mathrm{Na}$ TI Araweté/Igarapé Ipixuna, do povo Araweté, o desmatamento acumulado até 2010 foi de $43,73 \mathrm{~km}^{2}(0,47 \%$ da área dessa $\mathrm{TI}){ }^{15}$ Essa realidade mantém-se até o presente momento, com as terras indígenas sendo destaque nacional e internacional no que tange à proteção da natureza.

\section{Conclusões}

Tendências e rotinas distintas caracterizaram a relação entre o povo Kayapó e o "ambientalismo" nos processos políticos de disputa pelas

\footnotetext{
${ }^{15}$ Os dados desse parágrafo têm como fonte o projeto PRODES/INPE.
} 
terras ameríndias situadas em São Félix do Xingu-PA entre as décadas de 1970 e 2000.

Um primeiro período da relação entre os Kayapó e o "ambientalismo" antecede a década de 1980 e se caracteriza por duas tendências principais: 1) o desenvolvimento de uma percepção negativa entre os Kayapó quanto às dinâmicas de interação com a natureza típicas da sociedade brasileira, tidas por eles como prejudiciais à vida; e 2) a utilização episódica e periférica da retórica de proteção à natureza como justificativa para as propostas de demarcação territorial.

Os Kayapó, que historicamente consolidaram um modo de interação com os ecossistemas nativos caracterizado pelo baixo impacto da intervenção antrópica, pela promoção de heterogeneidade biológica por meio do manejo e por grande consciência cultural sobre as trocas energéticas entre humanos e natureza, ao confrontarem - sobretudo a partir da década de 1970 - a devastação ambiental característica da expansão da fronteira agropecuária no Brasil, diferenciaram-se dos "brasileiros" em sua autoconsciência social. Entretanto, essa oposição "ambientalista" não ganhou centralidade nas disputas pela terra travadas nesse período.

Três acontecimentos do final da década de 1980 marcaram o início das articulações diretas entre ameríndios Kayapó e grupos ambientalistas: a exposição "A ciência Mebêngôkre: alternativas contra a destruição", ocorrida em 1987; o chamado "1 Encontro das Nações Indígenas do Xingu", ocorrido em 1989 no município de Altamira-PA; e a turnê internacional promovida pelo cantor britânico Sting e a liderança Kayapó Raoni Metuktire, também em 1989.

Após esses eventos, a articulação direta entre os Kayapó e grupos ambientalistas passou a ser constante e a retórica da proteção à natureza passou a ocupar uma posição central na justificação das propostas de regularização territorial das áreas desse povo ameríndio situadas em São Félix do Xingu-PA. A rotinização desses dois novos padrões de interação "ambientalista" foi fundamental para as conquistas políticas obtidas com as homologações presidenciais das demarcações das terras indígenas do povo Kayapó.

Apesar disso, alguns subgrupos do povo Kayapó mantiveram-se inseridos em associações com madeireiras e mineradores para exploração irregular dos territórios ameríndios durante a década de 1990, o que foi utilizado midiaticamente para macular a imagem nacional e internacional dos Kayapó e fragilizar suas pretensões territoriais.

A partir da década de 2000, três tendências principais caracterizam a associação entre os ameríndios Kayapó e o "ambientalismo": 1) a diminuição do engajamento dos ameríndios em práticas degradantes; 2) a ampliação da busca dos Kayapó por iniciativas sustentáveis de produção e pelo combate à ocupação predatória de seus domínios; 3) a continuidade da manifestação das tradicionais práticas produtivas promotoras de diversidade biológica.

Com isso, uma interessante síntese entre "tradição" e "modernidade" passou a marcar o "socioambientalismo" Kayapó, cujo 
sucesso pode ser verificado pelas baixíssimas taxas de desmatamento materializadas nas TI desse povo nesse período (e até hoje).

Apesar de não serem as figuras idealizadas dos "bons selvagens", os ameríndios Kayapó estão bastante distantes das figuras também idealizadas de "destruidores da floresta". Eles são um povo ameríndio com heterogeneidades e contradições e construíram historicamente seu "socioambientalismo" a partir de disputas internas e externas ao povo. Partindo de uma materialidade existencial secular de baixo impacto antrópico nos ecossistemas, de promoção da heterogeneidade biológica através do manejo humano e de consciência da implicação profunda entre sociedade e natureza, os Kayapó ressignificaram suas relações com a natureza e incorporaram práticas e símbolos não ameríndios na orientação e justificação de suas ações. 
Espaço Ameríndio

\section{Referências bibliográficas}

ALMEIDA, M. W. B. DE. Direitos à floresta e ambientalismo: seringueiros e suas lutas. Revista Brasileira de Ciências Sociais, v. 19, n. 55, p. 33-52, 2004.

ALONSO, A.; COSTA, V.; MACIEL, D. A. Identidade e estratégia na formação do movimento ambientalista brasileiro. Novos Estudos, v. 79, n. Novembro, p. 151-167, 2007.

ANDRADE JÚNIOR, J. R. P. DE. Devastação ambiental e defesa da vegetação nativa: Brasil e as regiões de Ribeirão Preto-SP e São Félix do Xingu-PA. Tese de Doutorado em Sociologia. Universidade de São Paulo, 2020.

BANNER, H. Mitos dos índios Kayapó. Revista De Antropologia, v. 5, n. 1, p. 37-66, 1957.

BARRETO FILHO, H. T. et al. Apresentação do Dossiê: Antropologia das Áreas Protegidas e da Sustentabilidade. Anuário antropológico, v. 45, n. 1, p. 11-24, 2020.

BICALHO, P. S. DOS S. PROTAGONISMO INDÍGENA NO BRASIL: Movimento, Cidadania e Direitos (1970-2009). Tese de Doutorado em História. Universidade de Brasília, 2010.

CUNHA, M. C. DA; ALMEIDA, M. W. B. Populações tradicionais e conservação ambiental. In: CAPOBIANCO, J. P. R. et al. (Eds.). . Biodiversidade na Amazônia brasileira: avaliação e ações prioritárias para a conservação, uso sustentável e repartição de benefícios. São Paulo: Estação Liberdade : Instituto Socioambiental, 2001. p. 184-193.

DRUMMOND, J. A. A visão conservacionista (1920 a 1970). In: SVIRSKY, E.; CAPOBIANCO, J. P. R. (Eds.). . Ambientalismo no Brasil: passado, presente e futuro. São Paulo: Instituto Socioambiental: Secretaria do Meio Ambiente do Estado de São Paulo, 1997. p. 19-26.

GARFIELD, S. A Nationalist Environment: Indians, Nature, and the Construction of the Xingu National Park in Brazil. Luso-Brazilian Review, v. 41, n. 1, p. 139-167, 2005.

GREENPEACE. Parceiros no crime: a extração ilegal de mogno - a Amazônia à mercê de "acordos entre cavalheiros". 2001. Disponível em: $<$ https://documentacao.socioambiental.org/documentos/10D00483.pdf $>$.

LEA, V. R. Riquezas intangíveis de pessoas partíveis: os Mebêngôkre (Kayapó) do Brasil Central. São Paulo: Edusp, Fapesp, 2012.

MENEZES, M. L. P. Parque indígena do Xingu: a construção de um território estatal. Campinas: Editora da Unicamp, 2000.

NADASDY, P. Transcending the debate over the ecologically noble Indian: Indigenous peoples and environmentalism. Ethnohistory, v. 52, n. 2, p. 291-331, 2005. 
PIMENTA, J. Desenvolvimento Sustentável E Povos Indígenas : Os Paradoxos De Um Exemplo Amazônico. Anuário Antropológico, v. 2002-2003, p. 115-150, 2004.

POSEY, D. A. Os Kayapós e a natureza. Ciência Hoje, v. 2, n. 12, p. 35-41, 1984. Indigenous management of tropical forest ecosystems: the case of the Kayapó indians of the Brazilian Amazon. Agroforestry Systems, v. 3, p. 139-158, 1985. Ciência Kayapó: alternativas contra a destruição. In: Ciência Kayapó: alternativas contra a destruição. Belém: Museu Paraense Emílio Goeldi, 1992. p. 19-43.

POSEY, D. A. Consequências ecológicas da presença do índio kayapó na Amazônia: recursos antropológicos e direitos de recursos tradicionais. In: CAVALCANTI, C. (Ed.). . Desenvolvimento e natureza: estudos para uma sociedade sustentável. Recife: INPSO/FUNDAJ, Instituto de Pesquisas Sociais, Fundacao Joaquim Nabuco, Ministério de Educacao, Governo Federal, 1994. p. 177-194.

RIBEIRO, D. Os índios e a civilização. São Paulo: Círculo do Livro, 1985.

ROBERT, P. DE et al. A beleza das roças: Agrobiodiversidade Mebêngôkre- Kayapó em tempos de globalização. Boletim do Museu Paraense Emilio Goeldi: Ciências Humanas, v. 7, n. 2, p. 339-369, 2012.

SCHMINK, M.; WOOD, C. H. Contested frontiers in Amazonia. Nova York: Columbia University Press, 1992.

SCHWARTZMAN, S.; ZIMMERMAN, B. Alianças de conservação com povos indígenas da Amazônia. Megadiversidade, v. 1, n. 1, p. 165-173, 2005.

SEWELL JR, W. H. Lógicas da história: teoria social e transformação social. Petrópolis: Vozes, 2017.

TURNER, T. Da cosmologia à história: resistência, adaptação e consciência social entre os Kayapó. Cadernos de Campo, v. 1, n. 1, p. 68-85, 1991.

VERSWIJVER, G.; GORDON, C. Mebêngôkre ( Kayapó ). Disponível em: $<$ https://pib.socioambiental.org/pt/Povo:Mebêngôkre_(Kayapó)>. Acesso em: 20 jun. 2019 .

VIDAL, L. Morte e vida de uma sociedade indígena brasileira: os Kayapó-Xikrin do rio Cateté. São Paulo: Hucitec, Edusp, 1977.

VIOLA, E. J. O movimento ecológico no Brasil (1974-1986): do ambientalismo à ecopolítica. Revista Brasileira de Ciências Sociais, v. 1, n. 3, p. 5-26, 1986.

Recebido em: 10/08/2021* Aprovado em: 01/12/2021* Publicado em: 23/12/2021 